\title{
The Water World of the Orang Suku Laut in Southeast Asia
}

\section{Cynthia Chou}

\begin{abstract}
This article explores how the Orang Suku Laut, an indigenous Malay roving fishing community, perceives the water world in Southeast Asia. Their rites of childbirth, naming and the enculturation of their young present invaluable ethnographic data that challenge us to develop new ways to conceptualise 'water spaces' as well as to widen our academic inquiry into the less understood ways of spatial imaginings.
\end{abstract}

KEYWORDS: Orang Suku Laut, maritime, environment, giving birth, naming

\section{INTRODUCTION}

$I^{\wedge}$ THE STUDY OF maritime cultures in Southeast Asia, little is known about the various groups of sea nomads who have regarded the watery and coastal areas of the region as their dwelling places for centuries. In this paper, I intend to discuss the ethnography of one of these groups, namely, the Orang Suku Laut (literally, People of the Sea) who refer to themselves as the orang asli (indigenous people) and the asli Melayu (indigenous Malays) of this vast maritime world. ${ }^{1}$ The purpose is to explore the way in which they perceive the water world in Southeast Asia to obtain an understanding that is in keeping with indigenous understandings of their maritime landscape. Moreover, it is to raise questions pertaining to the diverse yet equally compelling ways in which people feel, experience, and think about water in Southeast Asia. The challenge is for us to think about the 'nature' of water in Southeast Asia.

This paper takes as its point of departure the question: How do we understand the relation between people and their environment or in this case, their seascape? To begin with, caution must be exercised in simple expressions such as "the natural environment" because "in... conflating the two terms we

Department of Anthropology, University of Iowa, Iowa City, USA; cynthia-chou@uiowa.edu

${ }^{1}$ The Southeast Asian sea nomads comprise at least three major groupings, each geographically, culturally, and linguistically distinct. The three groups are (1) the Moken and Moklen inhabiting the Mergui Archipelago of Burma and the islands of south-western Thailand; (2) the Orang Suku Laut comprising a congeries of variously named groups who can be found in the Riau-Lingga Archipelago, Batam, the coastal waters of eastern Sumatra and southern Johor; and (3) the Sama-Bajau who form the largest grouping inhabiting the Sulu Archipelago of the Philippines, eastern Borneo, Sulawesi, and the islands of eastern Indonesia (Sather 1995: 240-252 and Sather 1997: 320-329). 
already imagine ourselves to be somehow beyond the world, and therefore in a position to intervene in its processes" (Ingold 2000: 20).

Ethnographic accounts of the Orang Suku Laut will demonstrate the need to think again our commonly held ways of understanding human cognition, perception and action towards the water world in Southeast Asia. Their narratives inspire the move to replace the conventional dichotomy of nature and culture with a perception of the dynamic synergy of "how the environment has influenced humans, and humans the environment" (Barnard 2014: 3).

The knowledge for this comprises a kind that differs greatly from conventional wisdom that is usually transmitted via authorized textual forms. Instead, it comes from a sensory education derived from learning by living in context. To understand what the water world of the mariners is telling us, a quick overview of their mastery of the local geography in past and present times at the start of this article forefronts issues of how they think about, experience, and engage with the maritime environment they inhabit and move through in their daily lives. Consequently, this promotes an inquiry into bigger questions concerning conceptions of space and spatial relations. Within the context of this inquiry, three crucial points in the seafarers' life cycle—giving birth, naming. and learning to perceive the seascape-will be explored to yield vital ethnographic data to elucidate how they perceive and engage with the water world. ${ }^{2}$

\section{The Orang Suku Laut}

The Orang Suku Laut consist of variously named groups located in the northern and southern gateways to the Straits of Melaka and the southern tip of the Malay Peninsula extending all the way into Batam and the Riau Lingga archipelago of Indonesia. They are also to be found in the estuaries of major rivers in eastern Sumatra and in the coastal and maritime waters of various islands in the South China Sea. For centuries, they have been sailing through the archipelagos. Hence, the sea and its adjoining coastal areas have always been home.

Today, the Indonesian and Singaporean authorities, like other governments attempting to administer nomadic and migratory people are exerting great pressure to quell their mobility. Systematic programs of directed change have been operationalized to re-orient them towards becoming sedentary and becoming citizens of the nation states with the obligation to observe notions of borders and boundaries. This negative top-down perspective of the seafarers has been an

\footnotetext{
${ }^{2}$ My initial fieldwork among the Orang Suku Laut in the Riau Archipelago of Indonesia began in 1991 and spanned 14 months. Subsequently fieldwork has been carried out on an annual basis for periods varying between a few weeks to three months. A combination of various research methods that includes participant observation, non-directive questions, open-ended interviews, and informal and guided conversations have been used for the collection of qualitative research data. Observations of unspoken actions, expressions, and gestures have all also yielded vital data to see the water world through the eyes of the mariners.
} 
impetus for many land-based communities to look condescendingly at them as a marginalized, backward and unprogressive people.

Historical records show that the mariners were not always given such lowly status. Their current marginal status is one that has been culturally and politically constructed through shifts in political rule and their attending social ideologies in the region. Until the middle of this century, their mobile seafaring lifestyles and knowledge of the waters of the region were highly valued by the power-holders of the early Malay states of the western Malay region and by the various sultanates that arose in coastal Borneo, the southern Philippines, and eastern Indonesia. They were in fact the key players and the building blocks for the sustenance of sedentary Malay communities. Their mastery of the aquatic regions enabled them to move about easily to exploit a range of maritime and coastal resources for their own needs as well as for the purposes of trade and exchange.

The disjointed and complex myriad islands in the archipelagos were extremely difficult and treacherous areas to navigate through. The area is and has since historical times been known for its merciless currents, monsoonal storms, crooked and narrow water passages as well as countless hidden shoals and reefs cum rugged rocks (Andaya 2010: 177-178). An in-depth knowledge of this seascape in their home waters gave the Orang Suku Laut an advantage over visitors to this area. With their superior knowledge of the seascape, they discovered new areas that enabled the establishment of numerous settlements. Crucial sea lanes were also secured and defended by them to generate trading wealth for the sustenance of the land-based communities. The mariners were also indispensable information-bearers who connected and integrated the wide and complex network of micro-polities that constituted the power base for the land-based rulers (Andaya 2010: 173-201). Furthermore, there were times when at the behest of Malay lords, they dutifully raided incoming ships to provide supplies for trade that were vital for the success of the Malay entrepôt (Andaya 2010: 181). Undoubtedly, their seafaring activities contributed significantly towards enabling the large-scale integration of the increasingly centralized polities that shaped and developed the political and cultural landscape of the Malay World (Benjamin 1986: 16). The Orang Suku Laut's services were indispensable and so highly valued that they became respected as "maritime subjects par excellence" (Wolters 1975: 10) by the Malay rulers. For this, they were duly granted possession of "the seas and what floated on them by hereditary feudal right from the Sultan of Johor" (Trocki 1979: 56).

Until the middle part of the last century, the sea nomads knew no other home than their boats. Pressures to curb their seafaring lifestyle began with the dominance of European colonialists in the region who categorized them negatively as pirates and criminals. The colonial administrators saw it as their "sacred obligation to ameliorate the moral condition" (Logan 1849: 466) of the mariners. To this day, the legacy of the European colonialists in cultivating a negative view of the sea nomads has remained. Pressures to transform the boat-dwelling 
mariners into sedentary land-based communities continue to this time by present state administrators. While some Orang Suku Laut have moved ashore, others persist in maintaining their seafaring lifestyle.

In spite of the unceasing pressures that are inducing the sea nomads to transform their way of life, they continue to distinguish themselves by identification with the sea itself. They speak of themselves as 'Orang Suku Laut' (People of the Sea) rather than orang darat (land people). The sea is regarded as an inalienable gift from their ancestors, and as such their occupancy of it cannot be separated, removed or alienated from them. They thus possess an identity that is capable of being carried anywhere in the vast maritime world and the region is mapped according to wherever and, however far their navigational skills take them to. Other local inhabitants of the region acknowledge the mariners as the orang asli (indigenous peoples), in other words the 'true,' 'genuine,' or 'real' inhabitants of the archipelagos. The seascape home of the Orang Suku Laut lies in what cartographers now call "Southeast Asia', but their perception of the waters where they live begins from a different premise. It is pertinent at this point of our discussion to examine the dynamics of their sense of belonging. Central to our discussion is thus of how to make sense of the Orang Suku Laut's perception of their aquatic home environment?"

\section{Conceptualizing The Environment}

The study of space has captured the attention of many researchers. Spatial relations in Southeast Asia have long underpinned and inspired major works on political organization in the region. Most notably, the thought provoking concepts of Stanley Tambiah's (1976) galactic polity, Benedict Anderson's (1991) imagined communities, Thongchai Winichakul's (1994) geo-body, and James C. Scott's (2009) Zomia have opened new discussions and debates that served to refine our understanding of space and spatial relations in Southeast Asia.

In the study of Southeast Asia though, the emphasis has been "on everything terrestrial with a concomitant neglect of aquatic aspects" (Boomgaard 2007: 1). As noted by Boomgaard, "Given the fact that water in its many forms is of critical importance in the region, this is a remarkable oversight. Water, particularly in the form of seawater, heavily influences (and has done so in the past) the fortunes of the region" (ibid.: 1). Even less justice has been done regarding the study of indigenous sea nomads and their perceptions of the watery regions of Southeast Asia. This concern was recently voiced by Scott who states that he regrets that he has had to forego a discussion of them in his work The Art of Not Being Governed. He noted that had he "the patience" and "impulse to comprehensiveness", they would have been included because the Orang Suku Laut and their water world "conjure[s] up a whole watery Zomia [because]... [t]he sea is bigger, emptier than the mountains and the forest" (2009: xiv). 
The water world of the Orang Suku Laut is indeed a space with an intricate matrix of ideas (Chou 2013: 46). The matrix encompasses not just a cultural conception of "space" but more importantly, it encompasses a water world in which the environment and humans have mutually influenced each other (Barnard 2014).

To conceptualize a division between 'nature' and 'cultural' in the water world of the Orang Suku Laut would be unfortunate. This is because of the assumption that there exists the separation of the naturally real from the culturally constructed. Such a dichotomy needs to be questioned if we are to comprehend people's own perceptions of the world. This essay is starting from the premise that ways of acting in the environment are also ways of perceiving it, and demonstrates that such a division does not exist for the Orang Suku Laut. The writings of Bateson (1973) and Lévi-Strauss (1974) sought to collapse the distinction between mind and nature, and they provide inspiration here. For the former, the world is opened up by a process of revelation. In comparison, the latter argues that it is the mind that obtains information from the world via a decoding process. This contrast is linked to what is called a "sensory education" (Ingold 2000: 22) that comprises an acquisition of clues comprising songs, stories, and narratives that guide and shape the perception of the world. There is an assertion that knowledge embedded in such perception result in "sentient ecology" (Anderson 2000: 116-17). It is not formalized knowledge. Instead, it is transmissible knowledge founded in the skills, sensitivities, and orientations that have developed through the long experience of conducting one's life through a process of development in a historically specific environment (Ingold 2000: 26).

There are at least two crucial aspects in how people conceptualize their perception of the environment. First, 'environment' is a relative term and calls for relational thinking. That is to say, there is no life form without an environment. Conversely, there is no environment in the absence of life forms (Gibson 1979: 8; Lewontin 1982: 160). An environment takes on its meaning and development in relation to human beings and vice versa. It is about "interagentivity" (Ingold 2000: 47). Secondly, the environment is an indivisible entity. It is forged by relations and as life goes on, there is the dynamism of growth and development. People inhabit what Shweder (1990: 2) calls "intentional worlds". That is to say, human beings are "environmentally situated agents" who are at once both "organisms within systems of ecological relations, and as persons within systems of social relations" (ibid.). Environments are thus brimming with life forces of agency and intentionality. The problem is that for those who belong to different intentional worlds, the same things in the same physical surroundings may have quite different meanings.

\section{Engaging The Water World}

Events and processes such as rites of passage marking the transition from one phase of life to another are all matters of fact in one's existence. For the Orang 
Suku Laut, giving birth, naming, and learning to perceive the seascape are embedded in a direct and mutually attentive interaction of the self with their water world. As life reveals itself, the water world is about engagement and not imposition; about dwelling and not building; and about embracing a view rather than formulating a view.

\section{Giving Birth}

Pregnancy and giving birth are among the most crucial rites of passage in the life cycle of the Orang Suku Laut and as such, it is strictly observed that these rites of transformation should be embedded in a direct and mutually attentive involvement of the self with the environment. A woman who has missed at least two menstrual cycles would usually call upon a bidan (midwife) to check if she is pregnant. If that turns out to be the case, then an agreement is swiftly established with the midwife to perform the delivery. Some uang muka (money up front or down payment) in the region of $\mathrm{Rp} 20,000$ and upwards is handed to the midwife to seal the agreement that she will be responsible for looking after the health of the future mother and infant before and just after the delivery. Much care is taken to engage an appropriate midwife. Preference is for a kinswoman from the same village, or from one's network of inter-related territories based on kinship ties (Chou 2010: 70). This is because midwives are closely associated with mediumship and their ilmu (all-encompassing knowledge) is believed to be aided by tutelary spirits. Hence, the midwife has to be someone who can be trusted not to use her ilmu to harm the pregnant woman and her baby. If the situation calls for the expectant mother to seek a midwife from a rival Orang Suku Laut group, then precautions are taken to safeguard her wellbeing with powerful jampi (spells) by her own kinspeople to counter any possible evil forces.

At the mid-point of a woman's pregnancy, her belly is massaged by the midwife to gauge when the delivery might occur. As the expected time approaches, visitations to the midwife increase to the point when the expectant mother is advised to remain in her village and when the midwife might decide to move to be in closer proximity to the woman.

Throughout the woman's pregnancy, the midwife is relied upon to offer advice. For example, on the best ways for the baby's parents to respect elements in the environment to safeguard the expectant mother and her child from injury or deformity. In the early stages of pregnancy, it is greatly stressed that the foetus is part of its mother's blood. In view of this, the mother has to observe certain dietary restrictions and certain ways of interacting with her environment. While she should not be denied any food she requests, it would be prudent for her to avoid eating fish that characteristically can sting, such as catfish. This is because fish that can sting are venomous and inherently dangerous. As pregnancy is already a dangerous situation, dangerous food is prohibited. There are other prohibitions unrelated to food. During pregnancy, the expectant mother must 
never sit directly on the ground or a floor. Land is for burial sites. A piece of cloth, a mat or a piece of paper must therefore necessarily be laid on these surfaces before she can safely sit down. This prohibition does not extend to sitting in a boat because one is safe at sea. In the sixth month, the baby receives the breath of life and transforms into a person.

In the course of my fieldwork, the amniotic fluid of Ramrah of Teluk Nipah burst and her contractions began. Her midwife, Suri from Pulau Nanga was summoned. The islands of Nanga and Teluk Nipah are opposite each other and within hailing distance. Although both islands are Orang Suku Laut territories, they belong to rival groups. Ramrah had little choice but to call upon Suri to be her midwife because Yait, the only midwife of the Orang Suku Laut community in Teluk Nipah had passed away.

When Ramrah's contractions started, she laid on the floor of the inner room in her house which stood on stilts over the sea. Her mother Yang, her sisters and other women from Teluk Nipah gathered by her side. In the outer room, the men from the community gathered to drink arak (an alcoholic beverage). Overall, the atmosphere was relaxed.

The men were there for at least two reasons. One was to "jaga" (be on the lookout for) the time of "air pasang belum" (when the sea level is rising). The other was to help push the child out of the mother's belly. The midwife's elder brother, Bolong had also been called to come over to help push the child out. He was well known for possessing strong hands. While waiting, Bolong offered Suri a glass of arak. Knowing that all eyes were upon her to deliver the infant safely because she was performing a delivery for a woman of a rival community, she was anxious that the delivery proceed smoothly. She declined the drink with the following reason:

"I cannot drink until the baby is delivered, otherwise I might feel too dizzy to be alert enough. This is a crucial matter of life and death. So far, all the babies I have delivered have never died."

While waiting for Ramrah's contractions to intensify, Suri performed several rituals to ward off birth demons. Looking at the heaving belly of the reclining imminent mother, she stepped across the woman's belly and started a swaying motion by repeatedly alternating her own weight from one foot to another. This continued for several minutes during which she delivered, silently, a "jampi sarat" (a powerful spell). Then, she used kapor (a white powder) to draw a white cross onto the hands of the expectant mother and on the door step of the delivery room. These white crosses were signs to protect the expectant mother from birth demons. Throughout this time, Suri was constantly splashing water on Ramrah from the waist downwards. Water in this context served as a medium for weakening boundaries (Endicott 1991: 136) in relation to the spells cast to facilitate the passage of the emerging baby. This act of splashing 
water was therefore to ease the delivery and a symbolic act of expecting to ritually bathe the infant that was soon to be delivered.

Ramrah's step-father Meen busied himself with throwing uncooked rice grains around the house. ${ }^{3}$ Meen like all Orang Suku Laut believes that as their territory intrudes into the realms of air, water, earth, and jungle, they together with their territory (Chou 2010: 66-68) must show signs of reverence to the spirits that live in all these realms and be protected from outside evil spirits. Hence, this rice scattering ritual was performed to appease the spirits to ensure the well-being of Ramrah and everyone else who was helping in delivering the baby. Rice has the added symbolism of the "condition of primordial plenty", indestructibility, procreation, and regeneration (Jacobsson 2005: 30-1).

Occasionally, Meen would jampi a glass of water for Ramrah to drink. At one point, Ramrah's older son wandered into the room where his mother laid. No one stopped him and his mother requested that he sit close by. She also asked for some rice. Morsels of rice were rolled by hand and fed to her by her sister, Tupai. Ramrah's husband Kulut entered with more rice and salt to feed his wife. To cool down the rising temperature in the room, Ramrah's mother Yang started fanning her daughter. After Ramrah's rice meal, she was given a cigarette to smoke while remaining in a reclining position.

Another of Ramrah's sisters brought out cigarettes for everyone to smoke. Areca nuts were also pounded and passed around with lime and sireh leaves for the group to chew. It is believed that the act of chewing a betel quid hastens delivery (Sather 1997: 276).

Suddenly, the men in the other room noted that it was almost "tukar pasang" (change in the tide). The tide was rising and they had to move into action to quickly "putar" (rotate, turn) Ramrah to an appropriate position to correlate herself to the changing seascape. She was lifted and turned to lie in another direction. She had been lying in a position which saw her head pointing backwards to the door of her house. Now, she was moved in a clockwise direction so that the back of her head no longer pointed towards the entrance of the door. Instead, she now lay diagonally across the room with the back of her head pointed towards a wall and her feet towards the opposite wall. It was believed that if they did not turn her to be in harmony with the rising tide, she would not be able to give birth. As Meen explained:

"If it were a doctor, if they place you in one direction to give birth, it would definitely be in that position. However, it is not the same for [us]. We have to look at the sea and the direction of the house in the sea. The woman giving birth has to be placed in accordance with the tide of the sea. If the direction is bad, the woman will not give birth. We have to look at the sea, and then the direction of the house to see if the woman would or would not be able to give birth."

\footnotetext{
${ }^{3}$ Uncooked and threshed rice grains were used in the ritual.
} 
While all of this was happening, Kulut and Yang began to unpick the stitches of a few pillows. These pillows were a cause of anxiety for the family now as Ramrah was trying to give birth. Again Meen explained:

"It is because while Ramrah was pregnant, she stuffed the pillows with cotton wool and sewed them up. How can the baby leave? According to our alam (world), if we want to give birth, how can we close things? Here is an example, if a woman is still pregnant and she carries on working - sewing things up or nailing things - when it is about time to give birth and she is in pain, we must open up everything that she has either sewn up or nailed together. Otherwise, she would not be able to give birth. Her husband will have to open up everything. Otherwise, we will say alam tidak ada (there will be no world). If we open up everything, then it follows that "it" will also open up and the child will also come out. If the mother is sick, we just tolak (push) and the baby will be able to come out."

This is similar to the case of the Orang Lom of Bangka in West Indonesia where according to Smedal (1989: 98) "there are... only two acts the expecting mother ought to perform in order to ensure an easy childbirth: (1) remove the stitches of something one has sewn while pregnant and (2) extract some/any nails which have been hammered into a wall or beam of one's house by either husband or wife during the pregnancy... [these acts are] one of sympathetic signature: Extraction facilitates expulsion."

When the time arrived for Ramrah's baby to be delivered, the midwife tied a piece of cloth tightly around the waist of the mother to quicken the child's exit. She then reached under Ramrah's sarong (wrapped skirt) and readied herself to take hold of the child when it emerged. All the women and men present helped push the infant out of the mother's belly. While some men pressed directly onto her belly in downward motions, others pressed their backs against the walls of the house and used their heels to press against the backs of those who were pushing the baby out of the mother's belly. This was to give extra strength to those who were directly pushing the baby out of Ramrah's belly. Meen cast a spell over another glass of water, and with the assistance Ramrah was able to drink some of it. The rest of the water was rubbed onto Ramrah's back. Meen cast spells over more uncooked rice and threw them around the house.

Suddenly, Ramrah's sister Tupai fainted while trying to push the baby out. There was much commotion. Immediately, Meen and Bolong turned their attention to jampi her and she was given lime water to drink to ward off evil spirits. Tupai regained consciousness. After the baby was delivered, Suri washed the infant in lime water. Lime water was specifically used for protection against evil spirits in the environment. This is because the distasteful acidity of the lime fruit is thought to incapacitate evil spirits so that they can be controlled once they have been absorbed (Endicott 1991: 138-40). 
As soon as the baby was delivered, the midwife blew water from her mouth over its body to begin its breathing. She then tied the umbilical cord with a white thread to prevent the child's breath from escaping through the navel. Following this, she washed the infant and swaddled it in a multi-coloured cotton sarong. Kapur was massaged onto the mother's belly to "prevent air from entering" her body. The sarong (in this case meaning placenta) of the baby was washed, stored in a plastic bag, and hung outside and high up on the door of his parents' house to dry. This was to prevent the dogs from eating it. At the age of three or four years old, the baby would have to eat the dried placenta. It could be eaten over a course of time in small portions or all at once. The dried placenta could be cooked in a variety of ways such as with vegetables, fish, or chili. The child's grandfather explained why the child would be strong if it ate its own placenta:

"If other people were to eat [the placenta], it would not be of any use because the sarong belongs to the child only. However, if you give it to the child who owns the placenta to eat it, and if you take a parang (short machete) and attempt to hack the child, there is no need to be afraid. The child will not be hurt. This is the adat (customs and traditional law) of the Orang Suku Laut. The child will not be wounded."

The mother observed the common practice of restoring her energy by getting up to eat rice with black pepper and a fried egg. As explained by Endicott, "eggs are the origins of birds, of course, and the bird is a common Indonesian conception of the soul, especially when detached from the body". Eggs are therefore "good essence receptacles" (1991: 139). To restore Ramrah's energy, her mother also prepared a boiled herbal drink. Within three days of the delivery, Ramrah had the choice of bathing or swimming in the sea to clean herself. The Orang Suku Laut pride themselves for being able to restore health without having to observe the Chinese practice of forty days of isolation, or the Malay practice of isolating the woman for forty-four days to regain her strength. Bathing in the sea is an important ritual act. It marks the woman's safe transit through a difficult and dangerous passage of life. Sea water is also deemed a powerful source of medicine and an antibiotic against threatening diseases. After Ramrah had swum in the sea, she went out fishing until dawn of the next day.

Three days after the delivery of the baby, Ramrah and Kulut were obliged to reciprocate their helpers in various ways. Before the birth of the baby, they had given their midwife Rp 20,000. After the delivery, she was presented with objects including yellow pulot (glutinous rice), a chicken, a set of clothes, and a piece of cloth. Rice was pounded and distributed to those who pushed the child out of the mother's womb. These helpers had to look at the pounded rice and massage it slowly onto their limbs. Half a kilogram of rice was presented to each helper too. It was stressed that it was not the payment of money that had to be made. 
Rather, these were rituals that had to be observed, lest everyone would be sick. More specifically, it would mean that harm would befall their hands and legs. In addition, assam (tamarind), salt and nails was given to those who had jampi. This exchange was necessary to "lock" the ilmu to ensure the continuing effectiveness of the ilmu when it is applied again at a later date. Iron is believed to function as a boundary strengthener (Endicott 1991: 133) in that it possesses the power to keep a person's soul in the body. Thus, upon casting a spell, the giving of iron ensures that no vacuum is left for other spirits to enter.

After the delivery, the midwife spoke in private to Ramrah and Kulut. For the next forty days, Ramrah had to avoid eating fish that could sting such as ikan pari pari, ikan sembilang, and ikan tordak. She was also advised to be careful not to injure her foot on a wooden plank as this could result in life threatening bleeding. A kenduri (ritual meal) had to be held too.

A few days after the child was delivered, I visited Meen. Everyone had been speculating as to why Tupai had fainted while helping with the birth of her nephew. As Meen explained:

"We are all one kampong (village) here. On the surface, things are well, but not everyone is good to one another. The mouth is sweet, but we know who is bad. I do not want to harm the culprit back. If I wanted to, within three days', she would be in the "darat" (land) - grave."

Everyone refused to name the evil person in their midst. After much persuasion, all that they would say was that "the person with white hair" had done some "kong" (casting of a spell) because she wanted a certain person to die. However, the kong jumped onto Tupai instead. They accused "the person with white hair" of coming to watch and then leaving in the midst of everything without helping so that she could go home to do kong.

The environment bestows life to people. Bodies subsist only when they are engaged in the environment. Giving birth is one of the most intimate moments of intertwinement, interdependence, and interpersonal relations with forces such as spirits and organism such as sea creatures that collectively constitute the environment. Midwives must attend to the presence of these spirits and organisms in the knowledge that these spirits and organisms are attending to them as well. Based upon their skills, practice, intuition, and ilmu, midwives are expected to grasp cues and premonitions to advise a concordance or correction of behaviours for life to come into being. Any kinsperson who possesses the $i l m u$ and ability to understand this total field of relations, is expected to help bring life into being too. For the Orang Suku Laut, giving birth is a constitutive moment in the mutuality of a lived experience in the environment. In this way, midwives and kinspeople with relevant skills guide the actions of Orang Suku Laut parents-to-be. To be alive is to be situated within a field of relations in the environment. As these relations unfurl vigorously, life forms come into being. 


\section{Naming}

Children are conferred a personal name as soon as possible after their birth by their parents, or possibly, as a special courtesy, by a grandparent or an elder among their close kin. Harm would befall a child if it is left unnamed beyond the first few weeks of life.

I asked Kulut the father of the new-born baby in Teluk Nipah who would name his child. His response was:

"We do not know yet. We will depend on the child's grandfather and grandmother to decide. The names of all our three children were given by their grandparents. They will know which names would cocok (suit, fit, match) the children, and later, they will give the names to the children."

There are no formal name avoidances. Nonetheless, great wisdom must be exercised in naming a child. It must be done to ensure that the child will bear a name that will enable it to cocok the order of the maritime world. A name that is cocok secures energy from the environment, while an unsuitable name which defies forces in the environment will drastically affect one's health. Each name is therefore unique as it is a sign bearing a personal identity (Sather 1997: 279-280). In response to my question on how one decides a child's name, Bari, an Orang Suku Laut man from Pulau Senayang, answered, "I think and make connections".

From the perspective of the non-Orang Suku Laut, the very names of the sea mariners which "can never be found in books" clearly reveal their "backwardness" and "unprogressiveness". "The connections" that Bari, like all other Orang Suku Laut, takes such great care in making are viewed as the simple mindedness of the sea nomads. As expressed by Bapak Raja Rahim, an aristocrat from Pulau Penyengat:

"When [the Orang Suku Laut] are born, the first thing that comes to sight will be the name given to the child, for example, tree, torchlight and so forth. What kind of names are these?"

Contrary to views such as the above, the Orang Suku Laut say that names can be derived from various sources. From their perspective, one of the most important sources is to seek inspiration from the environment to form a name. A child must be given a name that would cocok with the water world they live in. Naming is a life sustaining process. Hence, each name is unique, imaginative, and breathes life. Examples include children in the Orang Suku Laut island of Nanga bearing names such as "Pasang" (rise of tide) and "Kahar" (all powerful or inevitable happening), and child in Pulau Senayang with a name such as "Nos" (a species of cuttlefish). In Teluk Nipah, parents Kasim and Ani named their child "Sotong" (another species of cuttlefish). Seafarers Musak and Muriah 
who lived mostly in their boats named their children "Oyek" (dish made from cassava), "Awang Belodok" (goby fish), Awang Ombak" (waves), "Isak" (crying or sobbing), "Sadah" (betel lime) and "Dogol" (without horns of a horned animals, without combs of a fowl, or stupid). These were names that evidently cocok the seascape as they sailed along their network of kin-related islands of Belakang Padang, Teluk Nipah, and Bertam. Names can also be compounded. Examples include "Siti-Payong" (Siti-umbrella) who is an Orang Laut woman from Nanga Island, or the second son of Kasim and Ani from Teluk Nipah named "Kemang-dor" (wild mango and the sound of gun-shot, or a supernatural being that attacks babies).

In the course of my fieldwork, a baby named Udin in the Orang Suku Laut island of Dapur Enam was constantly vomiting and sick. The island was located far out in the archipelago where few medical facilities were available. All sorts of spells were cast to restore the baby's health. Great efforts were even made to take the baby to a hospital. However, none of these attempts reaped any success. Finally, his grandmother decided to piara (adopt) him and nickname him "Udang" (shrimp). Everyone was instructed to call the baby by his nickname. Miraculously, there began signs of improvement in the baby's wellbeing.

In addition to given names, most Orang Suku Laut would acquire at least one if not several nicknames in the course of their lives. Nicknames are expressions of the peculiarities of a person's character or appearance; or they commemorate an important experience or relationship that the person has had with the environment. Nicknames that cocok will match the Orang Suku Laut with the order of the maritime world. These nicknames serve to safeguard one from evil agencies in the environment and ward off evil spirits. A person often becomes so much better known by his/her nickname to the extent they find it difficult to recall their official personal name. Yang Pendek, an Orang Suku Laut from Pulau Nanga, confided that she is called:

"Yang... but that is not my [official] name. I cannot remember my [official] name. People here call me Yang Pendek (short)."

Naming is a medium by which people interact with the landscape and a way to deal with dangers posed by the non-Orang Suku Laut world. Instead of trying to defy forces that threaten them, nicknames are also used to deceive and confuse potential enemy forces from knowing who one is referring to.

Today, as governmental and missionary efforts intensify to coerce the seafaring Orang Suku Laut into a sedentary lifestyle on land. They are also being directed to adopt more "progressive" names that appear in books. Many new names given to the mariners derive from Islam or Christianity. "Bolong" (black hole) the headman of the Orang Suku Laut at Pulau Nanga was renamed "Mohammad" and his brother "Ceco" was renamed "Ali" by officials from the Department of Social Affairs working in cooperation with Islamic missionaries. 
In Tiang Wang Kang, Christian missionaries baptized the Orang Suku Laut and gave them names such as "Amos" and "Mary". Most of these names are repeatedly given to members of the same Orang Suku Laut community as well as to those belonging to rival groups. It is notable though that on a daily basis, the Orang Suku Laut persist in using their own naming system.

Cynthia: "What is Asnah's husband's name?"

Yang Pendek: "Awang Keladi. His [official] name is Iskandar, but people call him Awang Keladi."

Most of the time, these given official names are used only when governmental or religious authorities are visiting. These names have very little relevance to the reality of their maritime world.

\section{Learning to Perceive the Seascape}

From an early age, Orang Suku Laut children sail with their parents from place to place, learning as they go about the topography and maritime life of the archipelago, while being told by their elders of the totemic significance of the various localities visited. Almost every locality has its story of how it was founded by their ancestors. The sea is a water world crisscrossed with records and marks of their ancestors' navigational activities (Chou 2010). Every fresh-water well along the coast tells a story of its formation; every mangrove swamp contains stories of different maritime species or the rise of the charcoal industry; and the jutting rocks in the seascape reveal important homes of the hantu laut (sea spirits).

Places possess meaning at different levels. Some are places where memory persists that these are territories that are inalienable gifts from their ancestors; while others are known for being particularly rich fishing spots. Some places mark deep personal experiences, others are places of fundamental spiritual potency with the hantu laut (sea spirits). On all of these levels - historical, personal, and spiritual - the landscape are dwelling places inscribed by the lives of all those who dwelt therein. These seascape stories are related or enacted through rituals observed by the elders. Through rituals, children witness their ancestors emerging from the seascape which is the anchor for their social relationships, territorial ownership, and rights in the maritime world. Children quickly learn to recognize that inalienable to the seascape are their ancestors and that they and their ancestor's movements in the water world are linked together in perpetuity.

The case of the Orang Suku Laut bears close semblance to that of Lowe's (2003) mesmerizing ethnography of the Sama, a sea people in the Togean Islands of Central Sulawesi. For the Sama, places are formed through movement and experience in space. Senses of place are based on the premise that "experience enters a body and gives rise to the existence of bodies that know places, and places that are shaped by these bodies" (ibid.: 128). In brief, knowledge of locality, community, and region for the Sama people is acquired through tactile 
experience. Their lives and identity are defined through interactions between social and physical inter-linkages.

In observing the daily fishing activities of their parents and older siblings, Orang Suku Laut children quickly learn that creatures of the sea are endowed with powers of feeling and autonomous action. In short, maritime creatures such as fish are endowed with characteristic behaviours and sensibilities. Insights to these characteristics are gained through one's daily interactions with maritime creatures. In this regard, dealing with inhabitants of the sea world is fundamentally similar to interacting with fellow humans. Inspiration can be drawn from Schutz's (1970: 163) work on sociality where he asserts that "Socialty is constituted by communicative acts in which the I [in this case the Orang Suku Laut] turns to others [maritime creatures], apprehending them as persons who turn to him, and both know of this fact." The Orang Suku Laut possess the capacity to narrate such encounters only because they are deeply situated in the water world and enmeshed in an intriguing nexus of relations with both human and non-human constituents of the seascape. The Orang Suku Laut understand that there is a common denominator between them and all things in the maritime world, and that everything is alive and situated within a field of relations.

The practice of showing and observing the seascape is an important one. As astutely observed by Ingold (2000: 21-22):

"To show something to somebody is to cause it to be seen or otherwise experienced - whether by touch, taste, smell or hearing - by that other person...In that way, truths that are inherent in the world are, bit by bit, revealed or disclosed to the novice. What each generation contributes to the next, in this process, is an education of attention (Gibson 1979: 254). Placed in specific situations, novices are instructed to feel this, taste that, or watch out for the other thing. Through this fine tuning of perceptual skills, meanings immanent in the environment that is in the relational contexts of the perceiver's involvement in the world - are not so much constructed as divorced...Through their sensory education, are furnished with keys to meaning."

In this manner, Orang Suku Laut children are gradually socialized to learn about the truths inherent in the seascape. Knowledge about the seascape is passed down the generations by way of its encoding in material symbols. When children are brought into the presence of some significant aspect of the seascape and called upon to attend to it in a certain way, their task is to discover for themselves the meaning that lies within it. As described by Nelson (1983: 239):

"Reality is not the world as it is perceived directly by the senses, reality is the world as it is perceived by the mind through the medium of the senses. Thus, reality in nature is not just what we see, but what we have learned to see." 
The Orang Suku Laut do not have cadastral maps. They obtain their bearings from attending the seascape. Knowledge of the water world is gained by traversing the archipelago, exploring it and being alert to the signs, symbols, and signals by which they are revealed. Learning to perceive the seascape is therefore not the case of mentally constructing the environment. Rather, it concerns acquiring the abilities "for direct perceptual engagement with its constituent, human and nonhuman, animate and inanimate" (Ingold 2000: 55). New knowledge is therefore acquired via creative acts of discovery rather than imagining.

From a young age, the Orang Suku Laut learn to perceive the maritime world as opening out to them. Hence, in their practices, they do not seek to transform the water world. Instead, they perceive the water world as a source of knowledge from which they seek revelation. The truths inherent in the water world are thus gradually revealed to their children as they advance from just knowing to a deeper knowledge of "inside" understanding (Myers 1986).

\section{Conclusion}

The water world is not simply a physical setting for the Orang Suku Laut. Rather, it is a world made for them in which they have a well-defined part to play and one in which they are intimately involved in a relationship of interdependence with the rise and ebb of tides, maritime creatures and flora, as well as sea spirits.

The water world is saturated with agency and intentionality. It will share its bounty reciprocally, in return for favours that are given to it, or for ongoing interpersonal dialogues that demonstrate respect. It is an elixir of life if one harmonizes with it through, for example, a name that is cocok with the order of things. Otherwise, the water world can be a deadly force. Hence, the Orang Suku Laut see themselves and all components of the water world interacting within a single all-embracing cosmic reality.

For the Orang Suku Laut, the water world is also embedded with the history of their ancestors, past activities, and social events. Altogether, these provide present inhabitants of the water world a specific point of origin and destiny. The past reverberates into the present via the water world. It is "life's enduring monument" (Ingold 2000: 54) and it constitutes each individual's personal and social identity. Alternatively put, the Orang Suku Laut inscribe their identities into the seascape. For them, the water world is an ordered network of kinrelated territories. It is a geography that articulates the movement of social life which has transformed the watery spaces into an environment of familiar routes and places.

The Orang Suku Laut's knowledge of the water world thus consists of their capacity to situate information that is revealed to them; and their ability to understand its meaning within the context of a direct perceptual engagement with their environment. Meaning is revealed via their systems of giving birth, naming, and 
learning to perceive the seascape. These systems of comprehending are in contrast to the common land-based or a non-Orang Suku Laut need to impose upon and conquer the water world before it can be regarded as an environment worthy of attention. It is precisely this difference in orientation to the environment that most fundamentally distinguishes the mariners from those who do not dwell in the watery regions. To borrow Ho's (1991) analogy of the ecological approach to perception, the waters of Southeast Asia is transparent and possesses depth. This is because the more one looks, the more one can see into it. At its most intense, all boundaries between self and other, as well as persons and objects, completely disappear. It is at this point that one discovers the real meaning of water in Southeast Asia.

\section{Acknowledgements}

The comments of Clifford Sather, Lindsay Lloyd-Smith, James Liang, and an anonymous reviewer for TRaNS have afforded me the opportunity to think of new ways for this article to come into being. I have benefitted much from their careful reading of an earlier draft and acknowledge with much appreciation their insights and advice.

\section{References}

Andaya, Leonard Y. 2010. Leaves of the Same Tree: Trade and Ethnicity in the Straits of Melaka. Singapore: National University of Singapore Press.

Anderson, David. 2000. Identity and Ecology in Artic Siberia. Oxford: Oxford University Press.

Barnard, Timothy P. 2014. “An Introduction”. In Timothy P. Barnard (ed.). Nature Contained: Environmental Histories of Singapore, pp. 1-8. Singapore: NUS Press.

Bateson, G. 1973. Steps to an Ecology of Mind. London: Fotana.

Benjamin, Geoffrey. 1986. "Between Isthmus and Islands: Reflections on Malayan Palaeo-Sociology." Sociology, Working Paper, No. 71. Singapore: National University of Singapore.

Boomgaard, Peter. 2007. "In a State of Flux: Water as a Deadly and Life-giving Force in Southeast Asia." In Peter Boomgaard (ed.). A World of Water: Rain, Rivers and Seas in Southeast Asian Histories, pp. 1-23. Leiden: Koninklijk Instituut voor Taal-, Land- en Volkenkunde Press.

Chou, Cynthia. 2010. The Orang Suku Laut of Riau, Indonesia: The Inalienable Gift of Territory. London and New York: Routledge Taylor and Francis Group.

Chou, Cynthia. 2013. "Space, Movement and Place: The Sea Nomads." In Satish Chandra and Himanshu Prabha Ray (eds.). The Sea, Identity and History: From the Bay of Bengal to the South China Sea, pp. 41-66. New Dehli: Manohar.

Endicott, Kirk M. 1991. An Analysis of Malay Magic. Singapore, Oxford and New York: Oxford University Press.

Gibson, J.J. 1979. The Ecological Approach to Visual Perception. Boston: Houghton Mifflin. 
Ingold, Tim. 2000. The Perception of the Environment: Essays in Livelihood, Dwelling and Skill. London and New York: Routledge Taylor and Francis Group.

Ho, M-W. 1991. "The Role of Action in Evolution: Evolution by Process and the Ecological Approach to Perception.” Cultural Dynamics 4(3), 336-354.

Jacobsson, B. 2005. Conquest of the Forest: Rice Rituals among the To Pamona in Central Sulawesi (Indonesia). Göteborg: Department of Social Anthropology, Göteborg University.

Lévi-Strauss, Claude. 1974. “Structuralism and Ecology," Social Science Information 12 (1), 7-23.

Lewontin, R.C. 1982. “Organism and Environment.” In H.C. Plotkin (ed.). Learning, development and Culture, pp. 151-170. Chichester: Wiley.

Logan, James R. 1849. "Malay Amoks and Piracies. What Can We do to Abolish Them?" Journal of the Indian Archipelago and Eastern Asia 3, 463-467.

Lowe, Celia. 2003. "The Magic of Place: Sama at Sea and on Land in Sulawesi, Indonesia." Bjdragen tot de Taal-, Land- en Volkenkunde 159(1), 109-133.

Myers, F. R. 1986. Pintupi Country, Pintupi Self: Sentiment, Place and Politics Among Western Desert Aborigines. Washington: Smithsonian Institution Press.

Nelson, R.K. 1983. Make Prayers to the Raven: A Koyukon View of the Northern Forest. Chicago, Ill: University of Chicago Press.

Sather, Clifford. 1995. "Sea Nomads and Rainforest Hunter-Gatherers: Foraging Adaptations in the Indo-Malaysian Archipelago." In Peter Bellwood, James J. Fox and Darrell Tryon (eds.). The Austronesians: Historical and Comparative Perspectives, pp. 229-268. Canberra: Australian National University.

Sather, Clifford. 1997. The Bajau Laut: Adaptation, History, and Fate in a Maritime Fishing Society of South-eastern Sabah. Kuala Lumpur: Oxford University Press.

Scott, James. 2009. The Art of Not Being Governed: An Anarchist History of Upland Southeast Asia. Yale: Yale University Press.

Schutz, Alfred. 1970. On Phenomenology and Social Relations. Chicago: University of Chicago Press.

Shweder, R. 1990. "Cultural Psychology: What is It?” In J.W. Stigler, R.A. Shweder and G. Herdt (eds.). Cultural Psychology: Essays on Comparative Human Development. Cambridge: Cambridge University Press.

Smedal, Olaf. 1989. Order and Difference: An Ethnography of Orang Lom of Bangka, West Indonesia. Oslo: Department of Social Anthropology, University of Oslo.

Tambiah, Stanley Jeyaraja. 1976. World Conqueror and World Renouncer. Cambridge and New York: Cambridge University Press.

Thongchai Winichakul. 1994. Siam Mapped: A History of the Geo-body of a Nation. Honolulu: University of Hawaii Press.

Trocki, C.A. 1979. Prince of Pirates: The Temenggongs and the Development of Johore and Singapore, 1784-1885. Singapore: Singapore University Press.

Wolters, O.W. 1975. The Fall of Srivijaya in Malay History. Kuala Lumpur: Oxford University Press. 